\title{
CURRENT TRENDS IN MICROBIAL PROFILE AND RESISTANCE PATTERN IN CSOM IN A SEMIURBAN HOSPITAL OF SOUTHERN INDIA
}

\author{
Upasana Bhumbla1, Pratima Gupta², Dinesh Raj Mathur ${ }^{3}$, Gyaneshwari ${ }^{4}$
}

${ }^{1}$ Senior Resident, Department of Microbiology, AIIMS, Virbhadra Marg, Rishikesh.

2 Professor and HOD, Department of Microbiology, AIIMS, Virbhadra Marg, Rishikesh.

3 Professor and Dean, Department of Microbiology, Shadan Institute of Medical Sciences, Peerancheru, Hyderabad. 4 Professor, Department of Microbiology, Shadan Institute of Medical Sciences, Peerancheru, Hyderabad.

\begin{tabular}{l} 
ABSTRACT \\
\hline BACKGROUND \\
Infections of the middle ear space and their sequelae have plagued mankind from the beginning of time. Since there are variations \\
in aetiological agents and their antimicrobial susceptibility patterns regionally. It is pertinent to carry out ongoing studies to observe \\
the profile of aetiological agents and their resistance patterns. This would help clinicians to prescribe appropriate and effective \\
antibiotics and prevent emergence of Multi-Drug Resistant (MDR) bacteria.
\end{tabular}

AIM

To study the spectrum of aerobic bacterial and fungal aetiological agents among patients clinically diagnosed as CSOM.

\section{METHODS AND MATERIAL}

This study was conducted on 105 patients of clinically diagnosed cases of CSOM attending ENT OPD of a semi-urban tertiary care level hospital. After proper sample collection by sterile aural swabs, they were immediately sent to the microbiology laboratory for aerobic bacterial and fungal culture, isolation and identification. Routine antibacterial susceptibility and detection of MRSA and ESBL was carried as per CLSI guidelines.

\section{RESULTS AND CONCLUSION}

The commonest age group affected was 10 months - 10 years (30/28.5\%), mainly affecting males (59.4\%). Patients were mainly from rural background (81.91\%) and majority of cases were reported in the months of May to August. Out of 105 patients, Gram negative isolates were $54(51.4 \%)$ and Gram positive isolates were 34 (32.4\%), 10 (9.5\%) were fungal isolates and remaining 12 $(11.4 \%)$ showed no growth. P. aeruginosa $(34.3 \%)$ was the predominant bacterial organism isolated followed by Staphylococcus aureus (28.6\%). Out of 30 isolates of S. aureus, 10 (33.3\%) were MRSA and out of 18 Gram negative isolates, 6 (33.3\%) were ESBL producers. Antibiogram of all isolates revealed that Amikacin was the most sensitive drug amongst all gram positive and gram negative organisms. Imipenem was the most sensitive drug among gram negative isolates, whereas Vancomycin was the most sensitive drug among gram positive isolates.

\section{KEYWORDS}

CSOM, MRSA, ESBL.

HOW TO CITE THIS ARTICLE: Bhumbla U, Gupta P, Mathur DR, et al. Current trends in microbial profile and resistance pattern in CSOM in a semiurban hospital of Southern India. J. Evolution Med. Dent. Sci. 2016;5(34):1917-1921,

DOI: $10.14260 /$ jemds/2016/454

\section{INTRODUCTION}

Chronic Suppurative Otitis Media (CSOM) is the most common childhood infections and is the most common cause of hearing impairment in the developing world. ${ }^{1}$ CSOM is characterized by drainage from the middle ear for at least two weeks and is associated with a tympanic membrane perforation that is usually painless. ${ }^{2}$ The aetiology of CSOM is complex, aerobic bacteria are responsible for $74 \%$ cases and the rest are anaerobes, fungi and mixed infections. Indiscriminate use of antibiotics and poor follow-up of patients may result in persistent low-grade infection and development of bacterial resistance leading to intratemporal and intracranial complications. ${ }^{2,3}$

Financial or Other, Competing Interest: None.

Submission 11-03-2016, Peer Review 06-04-2016,

Acceptance 12-04-2016, Published 28-04-2016.

Corresponding Author:

Upasana Bhumbla,

SR/JR Hostel, AIIMS Campus,

Virbhadra Marg,

Rishikesh-249201.

E-mail: ucupasana124@gmail.com

DOI: $10.14260 /$ jemds/2016/454
Since there are regional variations in aetiological agents and their antimicrobial susceptibility patterns, it is pertinent to carry out prospective studies to observe the profile of aetiological agents and their resistance patterns in order to prescribe appropriate and effective antibiotics and prevent emergence of Multi-Drug Resistant (MDR) bacteria.

\section{AIMS AND OBJECTIVES}

1. To study the spectrum of aerobic bacterial and fungal aetiological agents among patients clinically diagnosed to have CSOM attending ENT Outpatient Department (OPD).

2. To study the pattern of antibiotic sensitivity of isolates with special reference to Methicillin Resistant Staphylococcus Aureus (MRSA) and Extended Spectrum of Beta Lactamases (ESBL).

\section{MATERIALS AND METHODS}

The study was conducted over a period of 12 months (January to December). The study group comprised of 105 consecutive patients presenting with symptoms of CSOM to the ENT OPD in a semi-urban hospital of Southern India. Patients with symptoms of CSOM were evaluated as per the study protocol. 
The study was approved by Institutional Ethical Committee and written informed consent was taken from the patient/guardian.

\section{Inclusion Criteria}

All clinically diagnosed new cases of CSOM (Tubotympanic) of all groups and both sexes attending ENT Outpatient Department with history of prolonged otorrhoea (More than 2 weeks' duration) were included in the present study.

\section{Exclusion Criteria}

All diagnosed cases of otitis externa, foreign body in the external auditory canal, atticoantral type of CSOM and patients on antibiotics since last one week were excluded from the present study.

Details like age, gender, address, duration of ear discharge, etc. were noted in a case record form. Ear discharge was collected under all aseptic precautions using two sterile cotton swabs and transported to microbiology laboratory without any delay. One of the swabs was used for carrying out aerobic culture on $5 \%$ sheep blood agar, MacConkey agar and chocolate agar and incubated at $37^{\circ} \mathrm{C}$ for 48 hours. Second swab was used for fungal culture and inoculated on two Sabouraud's dextrose agar with Chloramphenicol and incubated at $37^{\circ} \mathrm{C}$ and $28^{\circ} \mathrm{C}$. Organisms isolated were identified using standard laboratory procedures. ${ }^{3-5}$

Antibiotic sensitivity testing was performed on Mueller Hinton Agar according to CLSI guidelines. MRSA was detected using Cefoxitin (30 ug) disc. ${ }^{6}$ and ESBL production in Gram negative bacteria was detected by using Potentiated Disc Diffusion Test (PDT).7,8

\section{RESULTS}

Ear discharge was collected from 105 patients diagnosed to have CSOM, of which 62 (59.1\%) were males and 43 (40.9\%) were females.

Age ranged from 10 months to 65 years with maximum number of cases seen between the age group of 10 months -10 years (30/28.5\%) as shown in Table 1. Cases of CSOM came mainly from rural areas (86/81.91\%) as compared to urban areas (19/18.09\%) and the peak season of CSOM (53/50.5\%) was observed during the month of May-August as shown in graph.

\section{Bacterial/Fungal Isolates}

Out of 105 cases, 93 (88.5\%) were culture positive for either bacterial/fungal growth. Out of these 93 cases, 83 (79\%) showed growth of bacteria and $10(9.23 \%)$ cases showed growth of fungi. No growth was observed in 12 (11.4\%) cases. Out of 83 bacterial culture positive cases, 78 were monobacterial and 5 were polybacterial and total bacterial isolates obtained were 88 out of 88 bacterial isolates; P. aeruginosa was the commonest $(36 / 34.3 \%)$ followed by $S$. aureus (30/28.6\%). Candida albicans 7 (6.7\%) and Aspergillus niger $3(2.8 \%)$ were the only fungi isolated as shown in Table 2.

\section{Antibacterial Susceptibility Profile}

Gram positive bacteria showed maximum susceptibility to Vancomycin and Amikacin, whereas gram negative isolates showed maximum susceptibility to Imipenem and Amikacin. P. aeruginosa isolates showed maximum susceptibility to
Imipenem and Ceftriaxone; $33.3 \%$ of S. aureus isolates were MRSA and $33.3 \%$ of Gram negative isolates were ESBL producers as shown in Table 3.

\begin{tabular}{|c|c|c|c|c|c|}
\hline \multirow{2}{*}{$\begin{array}{c}\text { Age } \\
\text { (Years) }\end{array}$} & \multicolumn{2}{|c|}{ Male } & \multicolumn{2}{|c|}{ Female } & \multirow{2}{*}{$\begin{array}{l}\text { Total } \\
\text { (No. of } \\
\text { Cases) }\end{array}$} \\
\hline & $\begin{array}{l}\text { No. of } \\
\text { Cases }\end{array}$ & $\%$ Age & $\begin{array}{l}\text { No. of } \\
\text { Cases }\end{array}$ & \% Age & \\
\hline $\begin{array}{c}10 \\
\text { months- } \\
10\end{array}$ & 19 & 30.9 & 11 & 25.5 & 30 \\
\hline $11-20$ & 18 & 28 & 09 & 22.9 & 27 \\
\hline $21-30$ & 14 & 22.5 & 06 & 13.9 & 20 \\
\hline $31-40$ & 04 & 6.4 & 09 & 20.9 & 13 \\
\hline $41-50$ & 04 & 6.4 & 04 & 9.3 & 08 \\
\hline $51-60$ & 02 & 3.2 & 02 & 4.6 & 04 \\
\hline$>60$ & 01 & 1.6 & 02 & 4.6 & 03 \\
\hline Total & 62 & $59.1 \%$ & 43 & $28.5 \%$ & 105 \\
\hline$T a l$ & $19 e$ & $d \operatorname{Sex} D i$ & but & CSON & ses \\
\hline
\end{tabular}

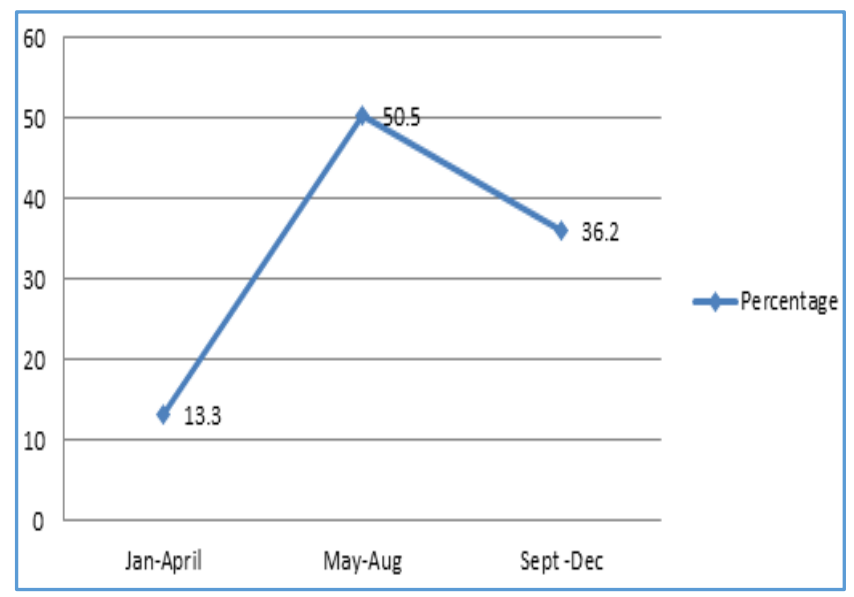

Graph Showing Seasonal Trend of CSOM

\begin{tabular}{|c|c|}
\hline Organisms & Total No. of Cases \\
\hline Monomicrobial & 33 \\
\hline Pseudomonas aeruginosa & 28 \\
\hline Staphylococcus aureus & 06 \\
\hline Proteus mirabilis & 05 \\
\hline Klebsiella pneumoniae & 04 \\
\hline Streptococcus pyogenes & 02 \\
\hline Acinetobacter spp. & 07 \\
\hline Candida albicans & 03 \\
\hline Aspergillus niger & 02 \\
\hline Polymicrobial & 01 \\
\hline P. aeruginosa + K. pneumoniae & 01 \\
\hline P. aeruginosa + S. aureus & 01 \\
\hline S. aureus + P. mirabilis & 12 \\
\hline K. pneumoniae + P. mirabilis & No growth \\
\hline \multicolumn{2}{|c|}{ Table 2: Distribution of Bacterial and } \\
Fungal Isolates (n=105) \\
\hline
\end{tabular}




\begin{tabular}{|c|c|c|c|}
\hline Antibiotics & $\begin{array}{c}\text { Gram } \\
\text { Positive } \\
\text { Isolates } \\
\mathrm{n}=\mathbf{3 4} \\
\end{array}$ & $\begin{array}{c}\text { Gram } \\
\text { Negative } \\
\text { Isolates } \\
\mathbf{n}=18 \\
\end{array}$ & $\begin{array}{c}\text { Pseudomonas } \\
\text { Aeruginosa } \\
\mathbf{n}=36\end{array}$ \\
\hline Vancomycin (VA) & $100 \%$ & - & - \\
\hline Clindamycin (CD) & $26.5 \%$ & - & - \\
\hline Linezolid (LZ) & $76.5 \%$ & - & - \\
\hline Erythromycin (E) & $55.9 \%$ & - & - \\
\hline Ampicillin(AMP) & $61.8 \%$ & - & - \\
\hline Amoxyclav (AMC) & $52.9 \%$ & - & - \\
\hline Ceftriaxone (CTR) & $73.5 \%$ & $55.6 \%$ & $72.2 \%$ \\
\hline Cefoxitin (CX) & $70.6 \%$ & - & - \\
\hline Cefotaxime(CTX) & - & $44.4 \%$ & - \\
\hline Ceftazidime(CAZ) & - & $38.9 \%$ & $61.1 \%$ \\
\hline Gentamicin(GEN) & $41.2 \%$ & $38.9 \%$ & $33.3 \%$ \\
\hline Amikacin (AK) & $82.4 \%$ & $72.2 \%$ & $69.4 \%$ \\
\hline Imipenem(IPM) & - & $94.4 \%$ & $86.1 \%$ \\
\hline $\begin{array}{c}\text { Piperacillin }+ \\
\text { Tazobactam }(\mathrm{TZP})\end{array}$ & - & $66.7 \%$ & $66.7 \%$ \\
\hline Cefpodoxime(CPZ) & - & $50 \%$ & - \\
\hline Ciprofloxacin(CIP) & - & $33.3 \%$ & $36.1 \%$ \\
\hline Netilmicin(NET) & - & - & $44.4 \%$ \\
\hline MRSA & $33.3 \%$ & - & - \\
\hline ESBL producers & - & $33.3 \%$ & - \\
\hline
\end{tabular}

\section{DISCUSSION}

CSOM is one of the most common ear problems encountered in a day-to-day ENT/Paediatric practice and if left untreated may cause hearing loss and other complications like mastoiditis, labyrinthitis, brain abscess, meningitis, lateral sinus thrombophlebitis, etc. The present study was conducted over a period of 12 months to evaluate the type of microorganisms and their antimicrobial susceptibility in cases of CSOM.

In the present study males (59.1\%) were affected more than female (40.9\%), which is in accordance to other studies. ${ }^{9}$ 11 , but in contrast to findings of some workers. ${ }^{12-15}$ where females were more affected than males. Since adult male and female ear has no anatomical differences, either sex can be equally affected.

Prevalence of CSOM was mainly seen in rural areas $(81.9 \%)$ as compared to the urban areas (18.1\%). Mohammad Y et $\mathrm{al}^{16}(84 \%)$, Srivastava A et al ${ }^{17}(80.3 \%)$, Aggarwal A et al ${ }^{10}$ $(56 \%)$ and $\mathrm{R}$ Shyamala et al ${ }^{11}(73 \%)$, also showed a predominance of cases from rural areas because of low socioeconomic status, lack of personal hygiene and poor educational status.

Maximum cases of CSOM were seen between the age group of 10 months - 10 years (30/28.5\%) and 11 to 20 years (25.7\%), wherein both accounted for $54.2 \%$ of the cases. This finding corroborates well with the observations made by other researchers. ${ }^{11,17-19}$ Higher prevalence of CSOM in children may be attributed to the fact that they are more prone to Upper Respiratory Tract Infections (URTIs) and due to relatively short Eustachian tube, infected material from the nose, adenoids and sinuses can more readily enter the Eustachian tube and to the middle ear, particularly during coughing, sneezing, vomiting, forced feeding and improper breast and bottle feeding a commonly practiced custom in our country. 20 Furthermore, cold weather predisposes children to URTIs which allows proliferation of pathogens leading to blockage of Eustachian tube. ${ }^{21}$
In the present study, prevalence of CSOM was mainly seen during the rainy season (50.5\%) of May-August in South India and even during September to December (36.2\%). Seasonal variations have been reported from both tropical and temperate regions. According to Ibekwe, inactive chronic otitis media becomes active during rainy season in West Africa and similar observation was also made in America and Europe during winter season. 22 In India, the disease is more commonly seen during rainy season. ${ }^{23-25}$

Analysis of the 105 ear swabs collected revealed that monobacterial growth was seen in $74.3 \%$, polybacterial growth was seen in $4.8 \%$, fungal growth was seen only in $9.5 \%$ and $11.4 \%$ samples showed no growth. Similarly, Poorey V K et al ${ }^{26}$ reported pure growth from $82 \%$, mixed growth in $10 \%$, and no growth in $8 \%$. Prakash $\mathrm{R}$ et al 17 from Uttarakhand reported monomicrobial aetiology in $51.84 \%$, polymicrobial growth in $33.33 \%$ and $8.82 \%$ showed no growth. In contrast, some researchers found polymicrobial aetiology more prominent in otitis media. ${ }^{20,25}$ Difference in results of various authors could have been due to the differences in the patient population group studied and geographical variations.

In the present study, P. aeruginosa $36(34.3 \%)$ was the predominant organism followed by S. aureus 30 (28.6\%). This finding correlates with almost all studies conducted in India and other tropical countries, where either one or the other is the predominant pathogen. In some of the Indian studies, P. aeruginosa followed by $S$. aureus were the predominant isolates. 9,26,27,28,29,30 whereas in others $S$. aureus followed by $P$. aeruginosa was the predominant isolate. ${ }^{17,21,31}$ Probably, it could be due to the fact that $\mathrm{S}$. aureus is part of skin flora and can gain entry easily into the middle ear and P. aeruginosa acts as an opportunistic pathogen and gain entry from outside through the perforation in tympanic membrane. Like other studies, our study revealed that both gram-positive and gramnegative organisms were responsible for infection of middleear and gram-negative rods outnumbered the gram-positive organisms in causing CSOM.17

Fungal infections of the middle-ear are common and the most commonly found fungi in CSOM are Candida species and Aspergillus species. Fungal growth obtained in the current study (9.23\%) included Candida albicans 7 (6.6\%) and Aspergillus niger $3(2.8 \%)$, which correlated with studies of Arvind $\mathrm{N}$ et al ${ }^{27}$ (2\%), Srivastava A et al 17 (1.9\%) and Prakash $\mathrm{M}$ et $\mathrm{al}^{29}(1.5 \%)$. Fungal infections are promoted due to poor hygienic conditions, environmental factors and previous use of antibiotics.

For better management of CSOM, aetiological identification of infection and conducting drug susceptibility tests are essential in guiding the physician to prescribe effective antimicrobials. From the analysis of the current study and comparison with the findings of other researchers, it is clear that microbial profile and antimicrobial sensitivity pattern of CSOM has been changing over a period of time. Geographical variations and difference in patient population could be the possible factors for variability. Indiscriminate antibiotic usage as well as negligence on part of the patient to continue taking antibiotics beyond the prescribed duration and dose promotes the emergence of antimicrobial resistance. Furthermore, Gentamicin and Ciprofloxacin ear drops are frequently prescribed to patients with CSOM and in our study it was observed that these were the least sensitive antibiotics, 
this may have been promoted by injudicious use of broad spectrum antibiotics.

Vancomycin (100\%) followed by Amikacin (81.2\%) were found to be the most sensitive antibiotics for gram positive isolates, which correlated with other studies. $17,27,32,33$

Imipenem $92.3 \%$ followed by Amikacin (61.5\%) were the most sensitive drugs for gram negative isolates and this was in concordance with the study of Arvind $\mathrm{N}$ et al ${ }^{27}$ and Chakraborty B et al. ${ }^{32}$

Imipenem $(84.8 \%)$ followed by Ceftriaxone were the most sensitive drugs for the P. aeruginosa isolates, which correlated with the study of Arvind $\mathrm{N}$ et al $^{17}$ and Aggarwal A et al. ${ }^{16}$ Other antibiotics like Amikacin, Ceftazidime, Piperacillin and Tazobactam were also sensitive to Pseudomonas, which correlated with the study of Chakraborty B et al, Bansal S et al and Raghavendra SG et al.32,33,34

Of $28 \mathrm{~S}$. aureus isolates, $33.3 \%$ were MRSA which is similar to prevalence observed by other workers. ${ }^{21,32,33,34}$ Of 18 Gram negative isolates, 33.3\% were ESBL producers which correlated with the study of Chakraborty B et al ${ }^{32}$ (28.6\%). Hence, periodic surveillance for microbial aetiology of CSOM and their antibiotic sensitivity pattern in a local area can guide clinicians in prescribing antibiotics for effective treatment of CSOM and thus minimizing its complications.

\section{REFERENCES}

1. Charles M Cummings. Textbook of Otolaryngology, Mosby year book, USA: chapter 157. 2006;2nd edition:2823-39.

2. Gulati SK. Investigative profile in patients of chronic suppurative otitis media. Ind J Otol 1997;3(2):59-62.

3. Miles RS, Amyes SGB. Laboratory control of antimicrobial therapy. In: Gerald Colle J, Barrie P, Andrew GF, Anthony S, editors; New Delhi, Mackie and McCartney Practical medical microbiology, 2007;14th edn:151-78.

4. Forber BA, Sahm DF, Weissfield diagnostic microbiology. In: Bailey and Scott's, Missouri, Mosby Elsevier, $1998 ; 13^{\text {th }}$ edn:238-42.

5. Washington CW, Stephen DA, William $M$, et al. In:koneman's colour atlas and textbook of microbiology. Philadelphia; Lippincott's williams and walkins, 2006; 6th edn:68-74.

6. Mohammed R, Mahmood Y, Ali F. Comparison of different laboratory methods for detection of methicillin resistant staphylococcus aureus. Pak J Med Sci 2006;22(4):44245.

7. Turng B, Votta M, Turner D, et al. Detection of extended spectrum beta-lactamase among enterobactericeae using phoenix automated microbiology system with BDX pert system. Presented at the inter science conference on antimicrobial agent and chemotherapy (ICCAC) San Diego, California 2002.

8. Gupta A, Prasad A, Ghoshal U, et al. Comparison of disc diffusion and double disc synergy method for the detection of extended spectrum beta-lactamases in enterobactericeae. Indian J Med Res 2008;128:209-11.

9. Madana J, Yolmo D, Kalaiarasi R, et al. Microbiological profile with antibiotic sensitivity pattern of cholesteaomatous chronic suppurative otitis media among children. Int J Paediatr Otorhinolaryngol 2011;75(9):1104-8.
10. Aggarwal A, Kumar D, Goyal A, et al. Microbiological profile and their antimicrobial sensitivity pattern in patients of otitis media with ear discharge. Ind J Otol 2013;19(1):5-8.

11. Shyamala R, Reddy P Sreenivasulu. The study of bacteriological agents of chronic suppurative otitis media-aerobic culture and evaluation. Journal of Microbiology and Biotechnology Research 2012;2(1):152-62.

12. Loy AHC, Tan AL, Lu PKS. Microbiology of chronic suppurative otitismedia in Singapore. Singapore Medi J 2002;43(6):296-9.

13. Mansoor T, Musani MA, Khalid G, et al. Pseudomonos aeruginosa in chronic suppurative otitis media: sensitivity spectrum against various antibiotics in Karachi. J Ayub College Abbottabad 2009;21(2):120-3.

14. Shrestha BL, Amatya RC, Shrestha I, et al. Microbiological study of chronic suppurative otitis media. Nepalese Journal of ENT Head and Neck Surgery 2011;2(2):6-7.

15. Prakash R, Juyal D, Negi V, et al. Microbiology of chronic suppurative otitis media in a tertiary care set up of Uttarakhand state, India. N Am J Med Sci 2013;5(4):2827.

16. Mohammed Y, Mujumdar KA, Akhtar K, et al. Clinical study of chronic suppurative otitis media with cholesteatoma. Bangladesh J Otorhinolargol 2011;17(1):42-7.

17. Srivastava A, Singh RK, Varshney S, et al. Microbiological evaluation of an active tubotympanic type of chronic suppurative otitis media. Nepalese journal of ENT Head and Neck Surgery 2010;1(2):14-6.

18. Wariso BA, Ibe SN. Bacteriology of chronic discharging ears in port harcourt, Nigeria. West Afr J Med 2006;25(3):219-22.

19. Poorey VK, Lyer A. Study of bacterial flora in CSOM and its clinical significance. Indian J Otolaryngol Head Neck Surg 2002;54(2):91-5.

20. Ahmad B, Hyadri AS, Afridi, et al. Microbiology of ear discharge in quetta. J Coll Physicians Surg Pak 2005;15(9):583-4.

21. Krista Vaidya, Madhup SK, Shrestha BL, et al. Bacteriological and mycological profile of chronicsuppurative otitis media among patients visiting dhulikhel hospital. Annals of Clinical Chemistry and Laboratory Medicine 2015;1(1):37-41.

22. Ibekwe O, Zain AS. Anaerobes and fungi in CSOM. J of Ann Otol Rhinol Laryngol 1997;106(8):649-52.

23. Wagh Kailash B, Ghule Shubhangi, Pawar SK, et al. Bacterial and fungal study in chronic suppurative otitis media from a developing country. INJCTR 2015;16(1):104-8.

24. Wakode PT, Joshi SV, Garwale SH. Chronic suppurative otitis media in school going children. Ind J of Otolaryngol and Head and Neck Surg 2006;58(2);152-5.

25. Maji PK, Chaterjee TK, Chaterjee $S$, et al. The investigation of bacteriology of chronic suppurative otitis media in patients attending a tertiary care hospital with special emphasis on seasonal variation. Ind J Otolaryngol and Head Neck Surg 2007;59(2):128-31. 
26. Saranya SK, Vazhavandal G, Vallab Ganesh B, et al. Bacteriological and mycological profile of chronic suppurative otitis media in a tertiary teaching hospital, trichy, Tamilnadu. International Journal of Pharmaceutical Science Invention 2015;4(1):13-9.

27. Arvind N, Chand P, Vishrutha KV. Microbiological profile of chronic suppurative otitis media. Int J of Biomed Res 2014;5(3):204-6.

28. Hirapure PV, Pote MK. Microbial profile and antibiogram of active patients of chronic suppurative otitis media in latur, Maharashtra, India. Int Res J Medical Sci 2014;2(5):6-9.

29. Sinha A, Kapil A, Gupta V. Aerobic bacteriological study of chronic suppurative otitis media. Ind J Otol 1999;5(4):203-6.

30. Kumar R, Aggarwal RK, Gupta G. Microbiological study of chronic suppurative otitis media. International Journal of Recent Scientific Research 2015;6(7):5487-90.
31. Prakash M, Lakshmi K, Anuradha S, et al. Bacteriological profile and their antibiotic susceptibility pattern of cases of chronic suppurative otitis media. Asian J of Pharmaceutical and Clinical Research 2013;6(3):210-11.

32. Chakraborty B, Subhadip D, Debashish G, et al. Changing trends of antibiogram profile in patients with community acquired chronic otitis media in a tertiary care hospital. J of Evolution of Med and Dent Sci 2014;3(45):11000-5.

33. Bansal S, Ojha T, Kumar S, et al. Changing microbiological trends in cases of chronic suppurative otitis media patients. Int J Cur Res Rev 2013;5(15):76-81.

34. Raghvendra SG, Mathew J, Mathew VA, et al. Microbiological pattern of ear swabs in chronically discharging ears in a tertiary care hospital in India. Indian J Otology 2013;19(2):51-4. 